\title{
Kanser Hastalarında Hastalık Algısının Değerlendirilmesi
}

\section{Evaluation of Cancer Patients Perception of Illness}

\author{
Elanur YILMAZ KARABULUTLU ${ }^{a}$, Seda KARAMAN ${ }^{b}$
}

\begin{abstract}
ÖZET Amaç: Bu araştırma kanser hastalarının hastalıklarını nasıl algıladıklarını ve bu algıyı etkileyen faktörleri belirlemek amacıyla yapılmıştır. Yöntem: Tanımlayıcı olarak yapılan bu araştırma Atatürk Üniversitesi Sağlık Araştırma ve Uygulama Hastanesi Medikal Onkoloji Kliniği’nde yürütülmüştür. Araştırma verileri Ocak-Eylül 2010 tarihleri arasında toplanmıştır. Araştırmaya belirtilen tarihler arasında klinikte yatarak tedavi gören 18 yaş ve üzerinde, Türkçe okuyabilen ve anlayabilen, araştırmaya gönüllü olarak katılan, araştırmaya katılmayı engelleyebilecek fiziksel ve zihinsel bir engeli bulunmayan 192 hasta dahil edilmiştir. Araştırmanın verileri soru formu ve Hastalık Algısı Ölçeği ile toplanmıştır. Bulgular: Hastaların hastalığın başlangıcından beri en fazla yorgunluk yaşadığı ve en çok bu belirtiyi hastalıkları ile ilişkilendirdikleri tespit edilmiştir. Hastaların hastalık hakkındaki görüşleri ile ilgili alt boyutlar incelendiğinde; kişisel kontrol algısı ve sonuçlar algısı puan ortalamalarının diğer alt boyutlara göre yüksek olduğu ve süre (döngüsel) algısı ve hastalığı anlayabilme puan ortalamalarının ise en düşük olduğu bulunmuştur. Hastaların en fazla hastalık nedeni olarak risk faktörlerini algıladıkları belirlenmiştir. Sonuç; hastaların hastalığın süresi, seyri ve tedavisi üzerindeki iç kontrol algılarının yüksek ve hastalığı anlama ve kavramalarının düşük olduğu belirlemiştir.

Anahtar Kelimeler: Hastalık algısı, hemşire, kanser
\end{abstract}

\begin{abstract}
Objectives: The purpose of this study is to determine how cancer patients perceive their illness and factors affecting the perception illness. Methods: The study was a descriptive and cross-sectional study. Data were collected Erzurum Atatürk University Research Hospital Medical Oncology Clinic between February and September, 2010. The study population was consisted of 192 cancer patients, who was over 18 years of age, who understand and can speak Turkish, without any psychiatric illness diagnosis and awareness of th eillness. Data collection tools were Patient Quastionnaire and İlness Percepitions Questionnaire. Results: Since the beginning of the disease patients experienced fatigue symptoms and associated this symptom with their illness. When examined subscales related to their views on the disease patients; the score mean for perception of personal control and perception of consequences all sub-scales regarding the patients' view on their illness, was higher in comparison to all other sub-scales of the scale. The score mean for perception of time (cyclical) and perception of illness coherence was the lowest. Risk factors attributions were determined as the most common reasons behind the patient illness. Conclusion; It is determined high internal control on duration of illness and course illness, treatment. It is determined low understanding of illness.
\end{abstract}

Keywords: Illness perceptions, nurse, cancer

\section{Giriș}

İnsanların sağlık ve hastalıklarıyla ilgili algıları ve bunların birbiriyle ilişkisinin belirlenmesinin sağlığı sürdürme, hastalikların önlenmesi, tedavi ve rehabilitasyon, tedaviye uyum ve hasta eğitiminde etkili girişimlerin planlanması ve uygulanması için önemi her geçen gün artmaktadır. $^{1}$
Hastalık kavramı hem objektif hem de subjektif boyutları içerdiğinden, benzer bir hastalıkla karşılaşan kişiler farklı tepkiler göstermektedir. ${ }^{2} \mathrm{Bu}$ farkı yaratan birçok faktör kişinin tepkisinde belirleyici rol oynar. Hastalar kişisel deneyimleri, bilgileri, değerleri, inançları ve gereksinmeleri 1şı̆̆ında hastalıklarını açıklamaya çalışırlar. Üstelik aynı hastalığa sahip olan insanların hastalık algıları

Geliş Tarihi/Received:20.04.2015/Kabul Tarihi/Accepted: 01.07.2015

a Sorumlu Yazar: Doç. Dr. Adres: Atatürk Üniversitesi Sağlık Bilimleri Fakültesi, İç Hastalıkları Hemşireliği Anabilim Dalı, e mail: elanurkarabulutlu@hotmail.com

b Arş. Gör. Adres: Atatürk Üniversitesi Sağlık Bilimleri Fakültesi, İç Hastalıkları Hemşireliği Anabilim Dalı, e mail: sd.krmn@hotmail.com 
farklılık gösterebileceği gibi sağlık profesyonellerinin de o hastalıkla ilgili algıları da farklılık gösterebilmektedir. ${ }^{3} \mathrm{Bu}$ nedenle her hastanın bireysel algisı değerlendirilmelidir.

Hastalık algısı hastaların hastalık hakkında sahip oldukları inançları ve hastalığın bilişsel görünümüdür. $\mathrm{Bu}$ temsiller hastalık hakkındaki fikirler ve algılarda değişimlere cevap olarak ortaya çıkan dinamik bir süreçtir. Bireye bir hastalık tanısı konduğu zaman genellikle kendi durumu hakkındaki inançları ile organize bir model geliştir. Bu da hastalığ 1 yönetmede önemli bir belirleyicidir. ${ }^{4}$ Hastalık algısı modeli hastalığı yorumlama, baş etme ve değerlendirme aşamalarını içeren döngüsel bir süreç olarak kabul edilmektedir. $\mathrm{Bu}$ model hastalığa bağlı ortaya çıkan semptomlar hakkındaki inanışlar, hastalığın dönemleri ve beklenen süresi, algılanan sonuçları, hastalığın tedavi ve kontrol edilebilirliği ve olası nedenleri ile ilgili özel inançları ortaya koymaktadır. ${ }^{4,5}$

Hastalar, hastalığın semptomları ile ilgili olarak ta benzer modelleri geliştirirler. ${ }^{6}$ Genellikle durumlarıyla ilişkilendirdikleri semptomlarda hastalıklarıyla ilgili temsiller kurarlar. Çoğu insan s1k görülen hastalıklar hakkında çeşitli semptomlar bilmektedir fakat farklı hastaliklara gelince net bir fikre sahip olmayabilir. Buna rağmen tanı aldıklarında hastalığın sebep olduğu semptomlar hakkında zamanla bazı inanışlar geliştirirler. Hastanın hastalığın semptomlarına bakış açısı, tedaviyi düzenleyen sağlık profesyonellerinin bakış açısından çok farklı olabilir. Hastalar sıklikla tedavinin yan etkileri hakkında ya da hiç ilișki olmasa bile görülen semptomlar hakkında yanlış yorumlar yapabilirler. ${ }^{3}$ Hastalık algısı bireylerin bir hastalığa yakalanma riskini azaltmak için nasıl davranacağını da etkiler. Sonuç olarak bir hastalıkla ilgili algılar bireylerin risk azaltıcı sağlıklı davranışlarının gelişimi için de önemlidir. ${ }^{7}$ Hastanın hastalığına ilişkin algısı, yorumu ve değerlendirmeleri; duygusal ve davranışsal tepkilerini, başetme biçimini, psikososyal durumunu ve yaşam kalitesini doğrudan etkilemektedir. ${ }^{2}$

Kanser, fiziksel, psikolojik, sosyal ve manevi boyutlar1 etkileyerek bireyin yaşamında önemli değişimler meydana getiren çok boyutlu bir olaydır. Kronik ve ciddi bir hastalık olmanın ötesinde, belirsizlikler içeren ağrı ve acı içinde ölümü çağrıştıran, suçluluk, terk edilme, panik ve kayg1 uyandıran bir hastalık olarak algllanmaktadır. $^{8}$ Öte yandan tedavi sürecinde ve sonrasında belirsizliğin oldukça yoğun yaşandığ 1 , bireyin psikososyal dünyasında yalnızca iz bırakmayan aynı zamanda anlamlı değişimler yaratan çok boyutlu bir yaşam deneyimidir. ${ }^{9} \mathrm{Bu}$ durumlar da hastalığın seyrini ve tedaviye yanit1 olumsuz etkilemektedir. Kanser hastalarının psikolojik kaygı ve acılarını azaltmak, tedaviye uyumunu sağlamak, yaşam kalitesini arttırmak, duyguların ifadesine yardımcı olmak ve hastalığın yarattığ1 çok yönlü krizle sağlıklı baş etmeye yardımcı olmak için hastaların kanseri nasıl algıladıkları ve bu algıyı etkileyen faktörlerin belirlenmesi önemlidir. Bu nedenle özellikle son yıllarda çok sayıda çalışma yapılmış olup, bu çalışmalarda kanser hastalarında hastalığa atfedilen anlamın ve algının farklı toplumlarda değişiklik gösterdiği, hastaların sosyodemografik, kültürel ve hastalık özelliklerinin hastaların algısında belirleyici olduğu da belirtilmektedir. ${ }^{11-21}$

Ülkemizde birçok kronik hastalık gruplarında yapılan konuyla ilgili çalışmalar mevcut olmasına karşın kanserli bireylerin hastalık algısının araştırıldığ sayıda çalışmaya rastlanılmıştır. ${ }^{22,23} \mathrm{Bu}$ nedenle bu araştırma kanser hastalarının hastalıklarını nasıl algıladıklarını ve bu algıyı etkileyen faktörleri belirlemek amacıyla yapılmıştır.

\section{Gereç ve Yöntem}

Tanımlayıcı olarak yapılan bu araştırma Atatürk Üniversitesi Sağlık Araştırma ve Uygulama Hastanesi, Medikal Onkoloji Kliniği'nde yürütülmüştür. Araştırma 
verileri Ocak - Eylül 2010 tarihleri arasında toplanmıştır. Araştırmanın evrenini belirtilen tarihler arasında klinikte yatarak tedavi gören 280 kanser hastas1 oluşturmuştur. Örneklem seçimine gidilmeden araştırmaya katılabilme kriterlerine uyan 192 hasta çalışmaya dahil edilmiştir. Araştırmaya katılabilme kriterleri 18 yaş ve üzerinde olmak, araştırmaya gönüllü olarak katılmak, araştırmaya katılmayı engelleyebilecek fiziksel ve zihinsel bir engeli bulunmamak, Türkçe okuyabilmek ve anlayabilmektir.

Araştırmanın verileri hastaların tanıtıcı ve hastalığa ait özelliklerini belirlemek amaciyla oluşturulan soru formu ve hastalık algısını belirlemek amacıyla Hastalık Algısı Ölçeği (HAÖ) ile toplanmıştır. Veriler hastalarla yüz yüze görüşme tekniği ile toplanmıştır. Görüşmeler yaklaşık $10 \mathrm{dk}$. sürmüştür.

Soru Formu: $\mathrm{Bu}$ form hastaların cinsiyet, yaş, medeni durum, eğitim durumu, aile tipi, çalışma durumu ve ailede başka kanser hastası varlığı gibi demografik özelliklerini ve hastalık tanısı, hastalık süresi, kemoterapi kür sayısı ve komorbid hastalık varlığ 1 gibi özelliklerini belirleyen sorulardan oluşmaktadır.

Hastalık Algısı Ölçeği (HAÖ):1996 yılında Weinmann tarafindan geliștirilmiș ve 2002 yılında Moss-Morris ve arkadaşları tarafindan yenilenmiştir. Ölçeğin Türk toplumunda geçerlik ve güvenirlik çalışmaları Kocaman ve arkadaşları tarafindan 2007 yılında yapılmıştır. ${ }^{24}$ HAÖ: hastalıktipi, hastalık hakkındaki görüşleri ve hastalık nedenleri boyutlarını içermektedir. 1) Hastalık Tipi Boyutu: Sik görülen 14 hastalık belirtisini (ağrı, boğazda yanma, bulantı, soluk almada güçlük, kilo kayb1, yorgunluk, eklem sertliği, gözlerde yanma, hırıltılı soluma, baş ağrısı, mide yakınmaları, sersemlik hissi, uyku güçlüğü, güç kaybı) içerir. Bu belirtilerin her biri için kişiye önce, 'hastalığın başlangıcından bu yana yaşayıp yaşamadığı', daha sonra 'bu belirtiyi hastalığıyla ilgili görüp görmediği’ sorulmaktadır. Bu boyut, her belirti için iki soruya da evet/hayır biçiminde yanıt verilecek biçimde düzenlenmiştir. Hastalık tipi boyutunda puan yüksekse hastanın hastalığa iştirak eden semptom sayısının yüksek olduğuna dair güçlü inancı olduğu ortaya çıkar. 2) Hastalık Hakkındaki Görüşleri Boyutu: Bu boyut yedi alt ölçeği içermektedir. Bunlar: süre (akut/kronik), sonuçlar, kişisel kontrol, tedavi kontrolü, hastalığ 1 anlayabilme, süre (döngüsel) ve duygusal temsiller olarak isimlendirilmiştir. Süre alt ölçekleri, kişinin hastalığının süresiyle ilgili algılarını araştırır ve akut, kronik, döngüsel olarak gruplanır. Süre (akut/kronik) alt boyutunda yüksek puan, durumun kronik olduğunu gösterir. Süre (döngüsel) alt boyutunda yüksek puan durumun siklik-döngüsel doğası olduğunu gösterir. Sonuçlar alt ölçeği, kişinin hastalığının şiddetine, fiziksel, sosyal ve psikolojik işlevselliğine olası etkileriyle ilgili inançlarını araştırır. Sonuçlar alt boyutunda yüksek puan, hastalığın negatif sonuçları olduğunu gösterir. Kişisel kontrol, kişinin hastalığının süresi, seyri ve tedavisi üzerindeki iç kontrol algısını araştırır. Tedavi kontrolü, kişinin, uygulanan tedavinin etkinliği hakkındaki inançlarını araştırır. Kişisel ve tedavi kontrol alt boyutlarında yüksek puan, kişinin hastalığ ve tedaviyi kontrol edebildiği hakkında pozitif inançlara sahip olduğunu gösterir. Hastalığı anlayabilme, kişinin hastalığını ne kadar anladığını ya da kavradığını araştırır. Hastalığ 1 anlayabilme alt boyutunda yüksek puan durumun kişisel anlaşılabilirliğini gösterir. Duygusal temsiller, kişinin hastalığıyla ilgili endişelerini araştırır. Duygusal temsiller alt boyutunda yüksek puan, hastalıkla provoke olan negatif duyguların arttığını gösterir. 3) Hastalık Nedenleri Boyutu: $\mathrm{Bu}$ boyut, kişinin hastalığının olası nedenleri hakkındaki düşüncelerini araştırır ve dört alt ölçek içerir. Bunlar, psikolojik atıflar (örneğin stres ya da endişe, aile problemleri, kişilik özellikleri), risk etkenleri (örneğin kalıtsal, sigara, alkol kullanımı, yaşlanma), bağışıklık (örneğin mikrop ya da virüs, vücut direncimin az olması), kaza veya şanstır (örneğin kaza, yaralanma, kötü talih 
vb.). Ölçeğin Türk toplumunda yapılan geçerlilik ve güvenilirlik çalışmasında hastanın hastalığ 1 hakkında görüşlerini içeren boyutun alt ölçeklerinin alfa katsayılarının $\quad 0.69-\quad 0.77$ arasında ve hastalık nedenlerinin alt ölçeklerinin alfa güvenilirlik katsayılarının 0.25-0.72 arasında değiştiği saptanmıştır. ${ }^{24} \mathrm{Bu}$ çalışmada ise hastanın hastalığı hakkında görüşleri içeren boyutun alt ölçeklerinin alfa katsayılarının 0.63 ile 0.92 arasında ve hastalık nedenlerinin alt ölçeklerinin alfa güvenirlik katsayılarının $0.54 \quad-0.68$ arasında değiștiği belirlenmiștir.

$$
\text { Verilerin Analizi ve }
$$

Değerlendirilmesi: Verilerin kodlanması ve istatistiksel analizleri bilgisayarda, SPSS 16.0 paket programında yapılmıştır. Hastaların tanıtıcı ve hastalığa ait özellikleri için yüzdelik testi kullanılmıştır. Elde edilen verilerin normallik analizi için grupta Kolmogorov-Smirnov Uyum İyiliği Testi uygulamıştır. Normal dağılım göstermeyen verilerde nonparametrik testlerden Mann-
Whitney $U$ ve Kruskal Wallis testi kullanılmıştır. Normal dağılım gösteren veriler için iki ortalama arasındaki farkın önemlilik testi kullanılmıştır. Hastalık süresi ve hastalık hakkındaki alt boyutları arasındaki ilişkiyi belirlemek için de korelasyon testi kullanılmıştır.

Araştırmanın etik ilkeleri: Araştırmanın yürütülebilmesi için Atatürk Üniversitesi Sağlık Bilimleri Fakültesi Etik Kurul'undan, Atatürk Üniversitesi Sağlık Araştırma ve Uygulama Hastanesi Başhekimliği'nden gerekli izinler alınmıştır. Hastalara çalışmanın amacı açıklanarak sözlü izinleri alınmıştır. Araştırma da gönüllülük ve gizlilik ilkesine bağlı kalınmıştır.

\section{Bulgular}

Hastaların tanıtıcı özellikleri incelendiğinde; hastaların \%54.7' $\operatorname{sinin}$ kadın, \%33.3' ünün 51-60 yaş aralığında, \% 70.3' ünün evli, \% 52.1' inin ilköğretim mezunu olduğu belirlenmiştir.

Tablo1. Hastalık tipi: Hastalık belirtileri ve hastalıkla ilişkilendirmesi

\begin{tabular}{|lcc|cc|}
\hline Belirtiler & $\begin{array}{c}\text { Hastalı̆̆ın başlangıcından beri bu } \\
\text { belirtiyi yaşadım }\end{array}$ & \multicolumn{2}{c|}{ Bu belirti hastalığımla ilgili } \\
& $\mathbf{n}$ & $\mathbf{n}$ & $\mathbf{\%}$ \\
\hline Ağrı & & & & 68.8 \\
Boğazda yanma & 133 & 69.3 & 132 & 20.8 \\
Bulantı & 45 & 23.4 & 40 & 54.2 \\
Soluk almada güçlük & 107 & 55.7 & 104 & 30.2 \\
Kilo kaybı & 63 & 32.8 & 58 & $\mathbf{7 4 . 0}$ \\
Yorgunluk & $\mathbf{1 4 4}$ & $\mathbf{7 5 . 0}$ & $\mathbf{1 4 2}$ & $\mathbf{1 5 2}$ \\
Eklem sertliği & $\mathbf{1 5 4}$ & $\mathbf{8 0 . 2}$ & 21 & 10.9 \\
Gözlerde yanma & 28 & 14.6 & 21 & 10.9 \\
Hırıltılı soluma & 31 & 16.1 & 25 & 13.0 \\
Baş ağrıları & 27 & 14.1 & 45 & 23.4 \\
Mide yakınmaları & 68 & 35.4 & 74 & 38.5 \\
Uyku güçlükleri & 95 & 49.5 & 75 & 39.1 \\
Sersemlik hissi & 81 & 42.2 & 95 & 49.5 \\
Güç kaybı & 99 & 51.6 & $\mathbf{1 4 1}$ & $\mathbf{7 3 . 4}$ \\
\hline
\end{tabular}


Tablo 2. Hastaların hastalık hakkındaki görüşler ve olası nedenler alt ölçeğinden aldıkları puanlar

\begin{tabular}{|c|c|c|c|}
\hline & $\mathbf{X} \pm \mathrm{SD}$ & Madde Sayısı & $\begin{array}{c}\text { Ölçekten alınan en } \\
\text { düşük ve en yüksek } \\
\text { değerler }\end{array}$ \\
\hline \multicolumn{4}{|l|}{$\begin{array}{l}\text { Hastalık hakkındaki } \\
\text { görüssler }\end{array}$} \\
\hline $\begin{array}{l}\text { Süre (akut/kronik) } \\
\text { algis1 }\end{array}$ & $15,82 \pm 6.80$ & 6 & $6-30$ \\
\hline Sonuçlar algisı & $23.00 \pm 4.75$ & 6 & $8-30$ \\
\hline Kişisel kontrol algısı & $24.09 \pm 5.44$ & 6 & $6-30$ \\
\hline Tedavi kontrolü algısı & $21.36 \pm 4.42$ & 5 & $5-25$ \\
\hline $\begin{array}{l}\text { Hastalığı anlayabilme } \\
\text { algisı }\end{array}$ & $15.77 \pm 5.32$ & 5 & $5-25$ \\
\hline Süre (döngüsel) algısı & $15.08 \pm 3.91$ & 4 & $4-20$ \\
\hline $\begin{array}{l}\text { Duygusal temsiller } \\
\text { algis1 }\end{array}$ & $22.63 \pm 6.45$ & 6 & $6-30$ \\
\hline \multicolumn{4}{|l|}{ Olası Nedenler } \\
\hline Psikolojik atıflar & $10.89 \pm 4.68$ & 5 & $6-28$ \\
\hline Risk Faktörleri & $12.48 \pm 4.28$ & 8 & $8-26$ \\
\hline Bağışı1klık & $3.42 \pm 1.99$ & 2 & $2-10$ \\
\hline Kaza yada Şans & $3.08 \pm 1.70$ & 2 & $2-9$ \\
\hline
\end{tabular}

Hastaların \%85.9' unun çalışmadığ $\% 69.8$ ' inin aile tipinin çekirdek aile olduğu, \%70.8' inde aile başka kanserli bireyin olduğu tespit edilmiştir. Hastalığa ait özellikler incelendiğinde; hastaların \%33.9' unun gastrointestinal sistem kanseri ve hastalık süresi ortalamasının ise $18.03 \pm 19.46$ ay olduğu, $\% 68.2$ ' $\operatorname{sinin} 5$ ve daha fazla kür kemoterapi aldığ 1 ve \%85.9' ununda başka bir hastalığın olmadığ 1 belirlenmiștir.

Hastalık algısı ölçeğinin hastalık tipi alt ölçeği incelendiğinde; hastaların hastalığın başlangıcından beri en fazla yorgunluk, kilo kaybı ve güç kaybı belirtilerini yaşadığ 1 ve bu belirtilerin hastalıkları ile ilgili olduğunu belirttikleri tespit edilmiştir. Hastaların en az hırıltılı soluma ve eklem sertliği belirtilerini yaşadığ 1 tespit edilmiş olup yaşanan tüm belirtilerden en az eklem sertliği ve gözlerde yanma belirtilerini hastalıkları ile ilişkilendirdikleri tespit edilmiştir.

Hastaların hastalık hakkındaki görüşleri ile ilgili alt boyutlar incelendiğinde; kişisel kontrol algısı ve sonuçlar algısı puan ortalamalarının diğer alt boyutlara göre yüksek olduğu belirlenmiştir. Süre (döngüsel) algısı ve hastalığ en düşük bulunmuştur. Hastalık nedenleri alt boyutu incelediğinde hastaların en fazla hastalık nedeni olarak risk faktörlerini gördükleri belirlenmiştir (Tablo 2).

Tablo 3 te hastaların taniticı ve hastalığa ait özelliklerine göre hastalık hakkındaki görüşler alt boyut ortalama puanları verilmiştir. Kadın hastaların duygusal temsil algısının yüksek olduğu belirlenmiştir $(p<0.001)$. Yaşın hastalık hakkındaki görüşler alt boyutlarından sonuçlar algısı, hastalığı anlayabilme algısı ve duygusal temsiller algisı ortalama puanlarını istatistiksel olarak etkilediği tespit edilmiştir $(\mathrm{p}<0.05) . \quad 41-50$ yaşları arasında olan hastaların sonuçlar algısı ortalama puanları en yüksek, 18-30 yaş arasında olanların hastalığ 1 anlayabilme algısı ortalama puanları en düşük ve 31-40 yaş arasında olanların ise duygusal temsiller algısı ortalama puanları en yüksek bulunmuştur. Evli olanların sonuçlar algısı ortalama puanlarının daha yüksek olduğu belirlenmiştir $(p<0.05)$. Çekirdek ailede yaşayan hastaların süre (akut/kronik) algısı ortalama puanları düşük kişisel kontrol algısı ortalama puanları ise yüksek bulunmuştur $(\mathrm{p}<0.05)$. 
Hastaların hastalık tipine göre hastalık hakkındaki görüşler alt boyut puan ortalamaları incelendiğinde; meme kanseri olan hastaların duygusal temsiller algisı ortalama puanları en yüksek, süre (döngüsel) algısı puanı en düşük bulunmuştur $(p<0.05)$. Ailede başka kanser hastası olmayanların sonuçlar algısı ortalama puanları yüksek olup fark istatistiksel olarak anlamlı bulunmuştur $(\mathrm{p}<0.05)$. Komorbid hastalığ 1 olanlarda süre (akut/kronik) algısı puan ortalamaları yüksek ve kişisel kontrol ve tedavi kontrol

\section{Tartışma}

Hastalık algısı kişilerin hastalık dönemleri boyunca yaşadıkları deneyimler, hastalık süreci, baş etme mekanizmaları üzerinde doğrudan etkisi olan bir kavramdır. Kişinin olayları nasıl algıladığının hastalığın gidişatına ve kişinin iyilik haline etkisi vardır. $^{2} \mathrm{Bu}$ nedenle çalışma kanser hastalarının hastaliklarını nasıl algıladıklarını ve bu algıyı etkileyen faktörleri belirlemek amacıyla yapılmıştır ve çalışma sonuçları ilgili literatür doğrultusunda tartışılmıştır.

Çalışmaya katılan hastaların hastalık algısı ölçeğinin hastalık tipi alt boyutu incelendiğinde; hastaların en fazla yorgunluk belirtisini yaşadığı ve yorgunluk yaşayan hastaların neredeyse tamamının bu belirtiyi hastalıklarıyla ilişkilendirdiği tespit edildi. Kayır' ın çalışmasında hastaların \%76.1 inin yorgunluk yaşadı̆̆ 1 ve $\% 63.8$ ' inin ise bu belirtiyi hastalıkla ilişkilendirdiği tespit edilmiştir. ${ }^{22}$ Kayış'ın çalışmasında ise hastaların \%76.7 $\operatorname{sinin}$ yorgunluk yaşadığ 1 ancak sadece \% 47.8 ' inin bu belirtiyi hastallğ 1 ile ilişkilendirdiğ $i$ belirlenmiştir. ${ }^{23}$ Yorgunluk kanserli hastalarının yaşadığ semptomlardan birisidir ve hastalarının yaklaşık 1/3'inde görüldüğü bildirilmektedir. ${ }^{25}$ Zordan ve ark. $^{26}$ hematolojik kanser hastalarının \%69' unda yorgunluğun görüldüğünü tespit etmiştir. Kanser hastalarının yaşadığı fiziksel yorgunluk ve güçsüzlük; beden işlevlerinde zayıflama ve duygusal alanda çevreye olan algısı ortalama puanları düşük bulunmuştur $(p<0.05)$. Hastalık süresi ile süre (akut/kronik) algıs1 ortalama puanları arasında pozitif yönde, kişisel kontrol ortalama puanları ile zayıf ve tedavi kontrol algısı ortalama puanları ile çok zayıf negatif yönde ilişki bulunmuştur $(p<0.001)$. Hastalık süresi arttıkça süre (akut/kronik) algıs1 ortalama puanları artmakta, kişisel kontrol ve tedavi kontrol algisi ortalama puanları ise azalmaktadır.

ilgiyi yitirme gibi sorunlara neden olmaktadır. $\mathrm{Bu}$ sorunlarda kanser hastalarında yaşam kalitesinin önemli oranda düşmesine neden olmaktadır. ${ }^{27} \mathrm{Bu}$ nedenle yorgunluk ve diğer semptomların tanilanmas1 ve hastaların semptomu nasil alg1ladıklarının belirlenmesi kanserli hastalarda bakım ve tedavinin etkinliğinin değerlendirilmesinde önemlidir.

Hastaların hastalık hakkındaki görüşleri incelendiğinde; en yüksek puanın kişisel kontrol algısı boyutunda olduğu belirlendi. $\mathrm{Bu}$ sonuç hastaların hastalığın süresi, seyri ve tedavisini kontrol edebildiği ile ilgili güçlü inançlara sahip olduklarını göstermektedir. Konu ile ilgili literatür incelendiğinde kanser hastalarında kişisel kontrol puanlarının genel olarak düşük olduğu tespit edilmiş olmasına rağmen ${ }^{15,17,19,20}$ kişisel kontrol algısının yüksek olduğu kısıtlı sayıda çalışmaya da rastlanılmıştır. ${ }^{21,23}$ Kanser tanısıyla birlikte birey, yaşamının tüm temel gerçeklerini ve kendi yaşamını anlayabilme ve kendi yaşamı üzerindeki kontrolü yeniden kazanabilmek için sorgulamaya başlar. ${ }^{28}$ Ayrıca bizim toplumumuzda özellikle hastallk dönemlerinde hasta bireye hem manevi hem de fiziksel destek artmaktadir. Tüm bunlar hastaların hastalık üzerindeki kontrol algisinın artmasina neden olabilir.

$\mathrm{Bu}$ araştırmada hastaların sonuçlar algıs1 puanları da kişisel kontrol algıs1 puanları gibi yüksek bulundu. $\mathrm{Bu}$ sonuç hastaların hastalığın şiddetine, fiziksel, sosyal ve psikolojik işlevselliğine olan etkileriyle ilgili olumsuz inançlarının 
yüksek olduğunu göstermektedir. Araştırma sonuçlarına benzer olarak Scharloo ve ark $^{14}$ baş ve boyun kanserli hastaların hastalığın negatif sonuçlarına ilişkin algılarının yüksek olduğunu bildirmiştir. Çağımızın önde gelen sağlık sorunlarından birisi olan kanser, çaresizlik ve belirsizlik içeren, ağrı ve acı içinde ölümü çağrıştıran ciddi ve kronik bir hastalık olarak algılanmaktadır. Akut hastalığın tedavisinde olumlu ya da olumsuz belirgin bir sonuç ortaya çıkarken, kanser gibi kronik bir hastalığın tedavisinde sonuç çoğu zaman daha az belirgindir. $\mathrm{Bu}$ nedenle kanser tanısı alan bireyin yaşadığ 1 duygular daha travmatiktir. ${ }^{29,30}$ Kanser tanısı birçok birey için varoluşun tehdidi anlamına gelir. Hastalık bireyin yaşamına yaşamı tehdit edici bir güç olarak girip kişinin hem fiziksel hem de ruhsal dünyasını tehdit etmeye başlar. ${ }^{28} \mathrm{Bu}$ duygular hastaların kanser hastalığının olumsuz algılamasinda etkili olabilmektedir. 
Tablo 3. Hastaların tanıtıcı ve hastalık özelliklerine göre hastalık hakkındaki görüşler

\begin{tabular}{|c|c|c|c|c|c|c|c|c|}
\hline Özellikler & $\mathrm{n}$ & $\begin{array}{l}\text { Süre } \\
(\text { Akut/Kr) }\end{array}$ & Sonuçlar & Kişisel kontrol & Tedavi kontrolü & $\begin{array}{l}\text { Hastalığ1 } \\
\text { anlayabilme }\end{array}$ & Süre döngüsel & Duygusal temsiller \\
\hline $\begin{array}{l}\text { Cinsiyet } \\
\text { Kadın } \\
\text { Erkek }\end{array}$ & $\begin{array}{l}105 \\
87\end{array}$ & $\begin{array}{l}16,52 \pm 7.23 \\
14,97 \pm 6.18 \\
t: 1.573 p>0.05\end{array}$ & $\begin{array}{l}23,43 \pm 4.46 \\
22.47 \pm 5.05 \\
\mathrm{t}: 1.406 \mathrm{p}>0.05\end{array}$ & $\begin{array}{l}23.55 \pm 5.65 \\
24.74 \pm 5.14 \\
t:-1.519 p>0.05\end{array}$ & $\begin{array}{l}21.02 \pm 4.57 \\
21.78 \pm 4.21 \\
\mathrm{t}:-1.175 \mathrm{p}>0.05\end{array}$ & $\begin{array}{l}15.12 \pm 5.29 \\
16.55 \pm 5.27 \\
t:-1.86 p>0.05\end{array}$ & $\begin{array}{l}15.13 \pm 3.72 \\
15.02 \pm 4.14 \\
\mathrm{t}: 194 \mathrm{p}>0.05\end{array}$ & $\begin{array}{l}24.20 \pm 5.94 \\
20.72 \pm 6.55 \\
\mathrm{t}: 3.860 \mathbf{p}<\mathbf{0 . 0 0 1}\end{array}$ \\
\hline $\begin{array}{l}\text { Yaş } \\
18-30 \\
31-40 \\
41-50 \\
51-60 \\
61 \text { ve üzeri }\end{array}$ & $\begin{array}{l}17 \\
15 \\
51 \\
64 \\
45\end{array}$ & $\begin{array}{l}14.00 \pm 7.60 \\
14.40 \pm 7.84 \\
15.54 \pm 6.44 \\
17.01 \pm 7.18 \\
15.60 \pm 5.94 \\
\text { KWU: } 4.571 \\
\text { p }>0.05\end{array}$ & $\begin{array}{l}22.05 \pm 4.52 \\
23.93 \pm 6.12 \\
24.33 \pm 4.21 \\
22.81 \pm 4.52 \\
21.80 \pm 4.99 \\
\text { KWU:9.482 } \\
\mathbf{p}<\mathbf{0 . 0 5} \\
\end{array}$ & $\begin{array}{l}24.11 \pm 6.29 \\
23.26 \pm 7.39 \\
24.29 \pm 4.93 \\
23.98 \pm 5.80 \\
24.28 \pm 4.53 \\
\text { KWU:,354 } \\
\text { p }>0.05 \\
\end{array}$ & $\begin{array}{l}21.52 \pm 5.40 \\
20.53 \pm 5.27 \\
21.21 \pm 4.39 \\
21.57 \pm 4.61 \\
21.46 \pm 3.56 \\
\text { KWU:2.189 } \\
\text { p }>0.05 \\
\end{array}$ & $\begin{array}{l}13.05 \pm 3.88 \\
14.13 \pm 4.76 \\
15.72 \pm 5.00 \\
16.87 \pm 5.87 \\
15.82 \pm 5.17 \\
\text { KWU: } 11.502 \\
\mathbf{P}<\mathbf{0 . 0 5} \\
\end{array}$ & $\begin{array}{l}16.41 \pm 2.31 \\
13.33 \pm 5.76 \\
14.98 \pm 3.50 \\
15.03 \pm 3.98 \\
15.35 \pm 3.92 \\
\text { KWU:2.768 } \\
\text { p }>0.05 \\
\end{array}$ & $\begin{array}{l}20.94 \pm 7.37 \\
26.53 \pm 4.95 \\
24.37 \pm 5.14 \\
22.56 \pm 6.28 \\
20.08 \pm 7.06 \\
\text { KWU:16.210 } \\
\text { p<0.05 }\end{array}$ \\
\hline $\begin{array}{l}\text { Medeni Durum } \\
\text { Evli } \\
\text { Bekar }\end{array}$ & $\begin{array}{l}135 \\
57\end{array}$ & $\begin{array}{l}15.91 \pm 6.76 \\
15.59 \pm 6.97 \\
t: .299 p>0.05\end{array}$ & $\begin{array}{l}23.50 \pm 4.40 \\
21.80 \pm 5.34 \\
\mathrm{t}: 2.284 \mathbf{p}<\mathbf{0 . 0 5}\end{array}$ & $\begin{array}{l}24.25 \pm 5.15 \\
23.70 \pm 6.10 \\
\mathrm{t}:, 647 \mathrm{p}>0.05\end{array}$ & $\begin{array}{l}21.39 \pm 4.28 \\
21.31 \pm 4.77 \\
\mathrm{t}:, 110 \mathrm{p}>0.05 \\
\end{array}$ & $\begin{array}{l}15.89 \pm 5.48 \\
15.47 \pm 4.94 \\
\mathrm{t}:, 502 \mathrm{p}>0.05\end{array}$ & $\begin{array}{l}14.89 \pm 4.06 \\
15.52 \pm 3.51 \\
\mathrm{t}:-1,020 \mathrm{p}>0.05\end{array}$ & $\begin{array}{l}23.05 \pm 5.99 \\
21.63 \pm 7.37 \\
\mathrm{t}: 1.397 \mathrm{p}>0.05\end{array}$ \\
\hline $\begin{array}{l}\text { Aile tipi } \\
\text { Çekirdek aile } \\
\text { Geniş aile }\end{array}$ & $\begin{array}{l}134 \\
58\end{array}$ & $\begin{array}{l}15.10 \pm 6.80 \\
17.48 \pm 6.57 \\
t:-2,246 \mathbf{p}<\mathbf{0 . 0 5}\end{array}$ & $\begin{array}{l}22.95 \pm 4.71 \\
23.10 \pm 4.87 \\
\text { t:- } 198 \mathrm{p}>0.05\end{array}$ & $\begin{array}{l}24.70 \pm 5.16 \\
22.67 \pm 5.84 \\
t: 2,409 \mathbf{p}<\mathbf{0 . 0 5}\end{array}$ & $\begin{array}{l}21.55 \pm 4.26 \\
20.93 \pm 4.77 \\
\mathrm{t}:, 904 \mathrm{p}>0.05\end{array}$ & $\begin{array}{l}15.75 \pm 5.42 \\
15.81 \pm 5.11 \\
t:-068 \mathrm{p}>0.05\end{array}$ & $\begin{array}{l}14.79 \pm 3.99 \\
15.75 \pm 3.64 \\
\mathrm{t}:-1,580 \mathrm{p}>0.05\end{array}$ & $\begin{array}{l}22.73 \pm 6.39 \\
22.39 \pm 6.62 \\
t:, 329 p>0.05\end{array}$ \\
\hline $\begin{array}{l}\text { Hastalık Tipi } \\
\text { Hematolojik Kanserler } \\
\text { Gís kanserleri } \\
\text { Akciğer Kanseri } \\
\text { Meme Kanseri } \\
\text { Baş boyun kanserleri } \\
\text { Diğer }\end{array}$ & $\begin{array}{l}14 \\
65 \\
21 \\
29 \\
22 \\
41\end{array}$ & $\begin{array}{l}15.71 \pm 8.42 \\
15.90 \pm 6.38 \\
16.33 \pm 5.94 \\
15.10 \pm 7.86 \\
15.95 \pm 7.94 \\
15.90 \pm 6.19 \\
K W: 1.853 \\
p>0.05 \\
\end{array}$ & $\begin{array}{l}23.35 \pm 5.15 \\
22.95 \pm 4.51 \\
23.23 \pm 5.78 \\
24.75 \pm 3.91 \\
21.59 \pm 4.43 \\
22.34 \pm 5.00 \\
\text { KW:4.189 } \\
\text { p }>0.05\end{array}$ & $\begin{array}{l}23.85 \pm 6.73 \\
23.95 \pm 4.85 \\
25.52 \pm 4.70 \\
24.51 \pm 6.54 \\
24.68 \pm 4.66 \\
23.04 \pm 5.83 \\
\text { KW:3822 } \\
\text { p }>0.05\end{array}$ & $\begin{array}{l}20.07 \pm 6.67 \\
21.73 \pm 3.81 \\
21.76 \pm 4.63 \\
21.65 \pm 3.70 \\
21.00 \pm 5.00 \\
21.02 \pm 4.59 \\
\text { KW: } 307 \\
\text { p }>0.05\end{array}$ & $\begin{array}{l}14.85 \pm 5.17 \\
15.84 \pm 5.46 \\
16.66 \pm 6.36 \\
15.34 \pm 4.46 \\
17.36 \pm 5.05 \\
14.95 \pm 5.30 \\
\text { KW: } 2.243 \\
p>0.05 \\
\end{array}$ & $\begin{array}{l}15.14 \pm 4.53 \\
16.00 \pm 3.44 \\
15.90 \pm 3.88 \\
13.93 \pm 3.99 \\
14.04 \pm 4.00 \\
14.56 \pm 4.08 \\
K W: 7.992 \\
\mathbf{p}<\mathbf{0 . 0 5} \\
\end{array}$ & $\begin{array}{l}22.64 \pm 6.45 \\
23.21 \pm 6.25 \\
19.66 \pm 7.33 \\
25.20 \pm 5.14 \\
22.04 \pm 7.10 \\
21.70 \pm 6.28 \\
\text { KW: } 8.089 \\
\text { p }<\mathbf{0 . 0 5}\end{array}$ \\
\hline $\begin{array}{l}\text { Ailede başka kanser varlığı } \\
\text { Var } \\
\text { Yok }\end{array}$ & $\begin{array}{l}56 \\
136\end{array}$ & $\begin{array}{l}15.75 \pm 6.42 \\
15.85 \pm 6.98 \\
\text { t: }-, 095 \mathrm{p}>0.05\end{array}$ & $\begin{array}{l}21.60 \pm 5.16 \\
23.57 \pm 4.46 \\
\text { t: }-2.64 \mathbf{p}<\mathbf{0 . 0 5}\end{array}$ & $\begin{array}{l}24.48 \pm 5.19 \\
23.93 \pm 5.55 \\
\text { t: }, 633 p>0.05\end{array}$ & $\begin{array}{l}21.44 \pm 3.64 \\
21.33 \pm 4.71 \\
\mathrm{t}:, 154 \mathrm{p}>0.05\end{array}$ & $\begin{array}{l}15.98 \pm 5.09 \\
15.68 \pm 5.42 \\
\mathrm{t}: 352 \mathrm{p}>0.05\end{array}$ & $\begin{array}{l}14.26 \pm 4.26 \\
15.41 \pm 3.71 \\
\mathrm{t}:-1.866 \mathrm{p}>0.05\end{array}$ & $\begin{array}{l}22.16 \pm 6.89 \\
22.82 \pm 6.27 \\
\text { t:- } 646 \mathrm{p}>0.05\end{array}$ \\
\hline $\begin{array}{l}\text { Komorbid hastalık varlığı } \\
\text { Var } \\
\text { Yok }\end{array}$ & $\begin{array}{l}27 \\
165\end{array}$ & $\begin{array}{l}19.03 \pm 6.81 \\
15.29 \pm 6.68 \\
\text { MWU: } 535.000 \\
\mathbf{p}<\mathbf{0 . 0 5}\end{array}$ & $\begin{array}{l}22.59 \pm 5.08 \\
23.06 \pm 4.71 \\
\text { MWU:2105.000 } \\
p>0.05\end{array}$ & $\begin{array}{l}21.44 \pm 6.08 \\
24.52 \pm 5.22 \\
\text { MWU: } 1530.000 \\
\mathbf{p}<\mathbf{0 . 0 5}\end{array}$ & $\begin{array}{l}19.74 \pm 4.78 \\
21.63 \pm 4.31 \\
\text { MWU: } 1677.000 \\
\mathbf{p}<\mathbf{0 . 0 5}\end{array}$ & $\begin{array}{l}15.88 \pm 4.51 \\
15.75 \pm 5.45 \\
\text { MWU: } 2201.500 \\
p>0.05\end{array}$ & $\begin{array}{l}14.96 \pm 4.06 \\
15.10 \pm 3.89 \\
\text { MWU: } 2221.000 \\
p>0.05\end{array}$ & $\begin{array}{l}21.70 \pm 6.32 \\
22.78 \pm 6.47 \\
\text { MWU: } 2000.500 \\
p>0.05\end{array}$ \\
\hline Hastalık süresi & & $\begin{array}{l}\mathrm{r}:, 191 \\
\mathbf{p}<\mathbf{0 . 0 0 1}\end{array}$ & $\begin{array}{l}\mathrm{r}:-, 014 \\
\mathrm{p}>0.05\end{array}$ & $\begin{array}{l}\text { r: }-, 303 \\
\mathbf{p}<\mathbf{0 . 0 0 1}\end{array}$ & $\begin{array}{l}\mathrm{r}:-, 222 \\
\mathbf{p}<\mathbf{0 . 0 0 1}\end{array}$ & $\begin{array}{l}\mathrm{r}:, 027 \\
\mathrm{p}>0.05\end{array}$ & $\begin{array}{l}\mathrm{r}:-, 068 \\
\mathrm{p}>0.05\end{array}$ & $\begin{array}{l}r:-, 065 \\
p>0.05\end{array}$ \\
\hline
\end{tabular}


Araştırmada en düşük puana sahip boyutun süre döngüsel alg1 boyutu olduğu belirlendi. $\mathrm{Bu}$ araştırma bulgusuna benzer olarak Kayış' ${ }^{23}$ çalışmasında da kanser hastalarının süre döngüsel puan ortalamaları en düşük bulunmuştur. Diğer önemli bir bulguda hastaların hastalığ anlayabilme algısının düşük olmasıdır. Hastaların hastalığ bilgilendirilmelerinden dolay memnuniyetleri arttıkça tedavi ve medikal tavsiyelere uyumunun $\operatorname{arttığ1} 1{ }^{31}$ olumlu hastalık algısının geliştiği ve buna bağlı olarak yaşam kalitelerinin yükseldiği tespit edilmiştir. $^{32}$ Hastanın sağlık bakım vericilerinden hastalığıyla başa çıkmasına yardımc1 olacak bilgi alması ve tedaviye bağlı olası yan etkiler hakkında bilgilendirilmesi hastanın kendisini iyi hissetmesine neden olduğu gibi, sağlığıyla ilgili pozitif davranış değişikliğini de beraberinde getiren önemli bir gereksinimdir. ${ }^{33}$ Bireyin hastalık hakkında bilgisinin yeterli olması baş etmesini kolaylaştıracağından ve felaketçi algılamayı engelleyeceğinden dolayı hastalık hakkındaki tepkilerini de olumlu yönde etkileyecektir. Hastaların en fazla risk faktörlerini hastalık nedenleri olarak algıladıkları saptandı. Risk faktörlerinden ise en fazla sigara hastalığın ortaya çıkışından sorumlu tutulmaktaydı. Kanser ve kanser risk faktörleri hakkında Türk halkının bilgi düzeyinin araştırıldığ 1 bir çalışmada bireylerin \%84' ünün kanserin nedeni olarak sigarayı gördüğü belirtilmiştir. ${ }^{30}$ Açıkgöz ve ark. ${ }^{34}$ yaptıkları çalışmada da katılımcıların \%90.8' inin sigaranın kansere neden olan etkenler arasında birinci sirada olduğunu ifade ettikleri belirtilmiştir.

Hastaların tanıtıcı ve hastalığa
ilişkin bazı özelliklerinin hastalık hakkındaki görüşleri alt boyutlarından bir veya birkaçında farklılık oluşturduğu belirlendi. Bu çalışmada kadın hastaların duygusal temsil algısının yüksek olduğu belirlenmiştir. Duygusal temsiller algısının yüksek olması kişinin hastalıkla birlikte ortaya çıkan duygusal etkinin özellikle negatif duyguların yüksek olduğunu göstermektedir. Kanser ciddi ve kronik bir hastalık olmanın ötesinde; korku, umutsuzluk, çaresizlik, terk edilme ve ölüm duygusu tepki ve düşüncelerini çağrıştıran bir hastalık olarak algılanmaktadır. $\mathrm{Bu}$ nedenle kanser bir yıkım gibi algılanır ve dramatik anlamıyla kişinin ruhsal dengesinde bozulmaya neden olur. ${ }^{35} \mathrm{Bu}$ alg1 kadınlarda daha belirgin olarak ortaya çıkmaktadır. Nitekim konuyla ilgili araştırmalarda bunu desteklemektedir. Kanser hastalarında psikolojik sorunların daha çok kadınlarda görüldüğü ve kadın olmanın psikolojik problemler için önemli bir risk faktörü olduğu belirtilmektedir. ${ }^{36}$ $\mathrm{Bu}$ nedenle hastaları anlayabilmek, yeni durumuna uyumunu kolaylaştırmak ve uygun girişimleri planlamak için duygusal durumu etkileyebilecek tüm etmenlerin belirlenmesi önemlidir. $\mathrm{Bu}$ araştırmada hastaların yaşının hastalığı algılamada önemli bir değişken olduğu ve 41-50 yaşları arasında olan hastaların sonuçlar algısının yüksek olduğu bulundu. Bu yaş döneminde; aile yapısında olan değişiklikler, meslek hayatında ulaşılan aşama, anne-babalarla olan ilişkiler, bedensel yaşlanma ve ölümün kaçınılmazlığının algılanması bir krizin yaşanmasına sebep olabilir. ${ }^{37}$ Tüm bu yaşananların yanında kanser gibi kabullenilmesi ve tedavisi oldukça zor bir hastalık tanısı alan hastayı uzun ve sıkıntılı bir tedavi dönemi beklemektedir. Bunlar hastaların yaşayabilecekleri krizi daha da arttırabilir ve hastaların geleceğe yönelik olumsuz algilarının artmasına katkı sağlayabilir.

Evli hastaların sonuçlar algısı yüksek bulunmuştur. Kanser sadece kişinin ruhsal ve fiziksel bütünlüğüne değil, aile sisteminin işlevselliğgine de etki eden bir hastallktır. Aile bireylerinden birisinin hayatı tehdit edici hastalığı karşısında, ailenin tümünün yaşam şekilleri, rol dağılımları ve beklentileri etkilenmektedir. ${ }^{38} \mathrm{Bu}$ nedenle evli olan bireylerin eş ve çocuklarının hayatının da 
değişeceği kaygısı ile hastalığın negatif sonuçlarını daha fazla algıladığı düşünülmektedir. Çekirdek ailede yaşayan bireylerin kişisel kontrol algıları yüksek ve süre (akut/kronik) algısı düşük bulunmuştur. Çekirdek ailede yaşayan hastaların kişisel kontrol algılarının yüksek olması süre (akut/kronik) algısını etkilemiş olabilir. Yani hastaların bu hastalıkla baş edebileceği, hastalıği ve belirtilerini kontrol altına alabileceği inancı ile hastalığın zamanla iyileşeceği ve uzun süremeyeceği inancının arttığı düşünülmektedir. Kronik hastalığın varlığı yalnızca ailenin yaşam biçimini değil, aynı zamanda aile içindeki atmosferi ve aile bireyleri arasındaki ilişkileri de etkileyebilir. Bu etki ilk olarak çekirdek aile içinde yaşanmaktadır. Bizim toplumuzda hastalık (özellikle kanser gibi ciddi bir hastalık) halinde aile bağları güçlenmekte ve hastaya olan destek artmaktadır. Hastanın algıladığ 1 desteğe bağlı olarak kontrol algısının arttığ düşünülebilir.

Hastaların hastallk tipine göre hastalık hakkındaki görüşler alt boyut puan ortalamaları incelendiğinde; meme kanseri olan hastalarin duygusal temsiller algis1 ortalama puanları diğer gruplara göre yüksek bulunmuştur. $\mathrm{Bu}$ sonuç meme kanseri olan hastaların hastalığa bağl1 negatif duyguları yoğun olarak algıladığını göstermektedir. Günümüzde meme kanseri, fiziksel yetersizlikler, psikolojik, mesleki ve cinsel sorunları içeren, kısa ve uzun süreli uyum bozuklukları yaratan bir hastalik olarak algilanmaktadır. ${ }^{39}$ Ülkemizde yapılan bir çalışmada da meme kanserli hastaların duygusal temsiller boyutu puanlarının diğer boyut puanlarına göre yüksek olduğu tespit edilmiştir. ${ }^{23}$ Psikososyal rehabilitasyon uygulanan meme kanserli hastalarda hastalık algısı ve psikososyal uyumun incelendiği bir çalışmada psikososyal rehabilitasyon öncesinde hastaların duygusal temsiller alt boyut puanları diğer boyutlara göre yüksek bulmuştur. ${ }^{40}$ Başka bir çalışmada da duygusal temsiller algısı ile mental sağlık arasında negatif korelasyon olduğu duygusal temsiller algısının hastaların mental sağlıklarını etkileyen önemli bir faktör olduğu belirtilmiştir. ${ }^{41} \mathrm{Bu}$ nedenle meme kanseri olan hastalarda olumsuz duyguların iyileştirilmesine yönelik girişimlerin yapılması gereklidir. $\mathrm{Bu}$ araştırmada meme kanseri olan hastaların süre (döngüsel) alg1sı en düşük bulundu. Süre döngüsel algısı hastalık belirtilerinin zaman içerisindeki farklılığını ve hastalığın iyi ve kötü dönemlerinin olup olmadığ 1 inancını içermektedir. Bu araştırma sonucu meme kanseri olan hastaların hastalığın zaman içerisinde farklılık göstermediğ $i$ inancının diğer hasta gruplarına göre daha düşük olduğunu göstermektedir. Çalışma grubundaki meme kanseri olan hastalarm yaşadıkları yoğun negatif duyguların bu sonuca katkı sağladığı düşünülmektedir.

Ailede başka kanser hastası olmayanlarda sonuçlar algısı ortalama puanları yüksek bulundu. Kanser için genelde söylenen, "trajik ve ölümcül hastalık" gibi toplumsal ve kültürel olarak atfedilmiş tanımlamalar ve kanserin önlenmesine yönelik çalışmalarda başvurulan "kanserle savaş" gibi tanımlamalarda kişilerin hastalık algısında olumsuz etkiler yapmaktadır. Bu nedenlerle kanser hastalık sürecinin nasıl olduğu ile ilgili fikri olmayan kişilerin bu toplumsal ön yargilardan etkilenerek kanserin olumsuz sonuçlarını daha yüksek olarak algıladıkları düşünülmektedir. Komorbid hastalığ olanlarda süre (akut/kronik) algısı puan ortalamaları yüksek ve kişisel kontrol ve tedavi kontrol algısı puanlarının düşük olduğu bulundu. Kanser yaşla birlikte sıklığ 1 artan bir hastalıktır. İleri yaşlarda aynı zamanda başka birçok komorbid hastalığın da görülme sıklığı artar. Komorbid hastalıklar kanser hastalarının yaşam süresi, yaşam kalitesi, tedavi toleransı ve hastaneye yatış oranları dahil birçok parametreyi etkilemektedir. ${ }^{42} \mathrm{Bu}$ nedenlerle komorbid hastalıkların, yaşam kalitesindeki düşmeye bağlı olarak hastalık üzerindeki kişisel kontrolün azalmasına ve tedavi toleransında azalmaya bağlı olarak ta tedavi üzerindeki kontrolün azalmasına 
neden olarak hastalığın uzun süreceği inancina katkı sağlayacağ1 düşünülmektedir. Hastalık süresi arttıkça süre (akut/kronik) alg1sı ortalama puanları artmakta, kişisel kontrol ve tedavi kontrol algısı ortalama puanları azalmaktadır. $\mathrm{Bu}$ sonuç hastalık süresi uzadıkça hastalığın kısa sürede geçemeyeceği algısının arttığını ve hastaliktan etkilenme düzeyinin artmasına bağ lı olarak ta bireylerin hastalık üzerindeki kontrollerinin azaldığına dair inançlarını göstermektedir. Araştırmayla benzer şekilde özofagus kanseri olan hastalarla yapılan bir çalışmada özofagus kanseri olan hastaların zaman içerisinde tedavi kontrol algılarının değiştiği ve hastalıkla geçirilen süre arttıkça hastalığın tedavi edilebileceği ile ilgili algılarının azaldığı belirtilmiştir. ${ }^{11}$

\section{Sonuç ve Öneriler}

Sonuç olarak araştırmada, hastaların en fazla yorgunluk semptomunu yaşadığ1 ve bu belirtiyi hastalıkları ile ilişkilendirdiğgi, hastalık üzerindeki kişisel kontrollerinin yüksek olduğu ve hastalığın döngüsel bir doğası olduğuna ilişkin inançlarının ve hastalığ 1 anlayabilme algılarının düşük olduğu, ayrıca risk faktörlerinin en sık hastalık nedeni olarak algılandığ sosyodemografik ve hastalığa ilişkin özelliklerin de hastaların hastalık algılarını farklı alt boyutlarda etkilediği belirlendi.

Araştırma sonucunda; hastaların algıladıkları semptomların iyileştirilmesine, kontrol duygusunu devam ettirmeye ve geliştirmeye yönelik hemşirelik girişimlerinin düzenlenmesi, hastalığın doğası ve hastalık, bu süreçte yaşanabilecekler ve tedavi ve yan etkileri hakkında bilgilendirilmesi, hastalarda mevcut olumsuz algının değiştirilmesine yönelik, hastalık ve tedaviyle ilgili yaşanan sorunları ortadan kaldıracak, hastalığa ve tedaviye uyumu arttıracak girişimlerin uygulanması önerilmektedir.

\section{Yazar Katkısı}

Çalışmanın tasarımı, literatür araştırması, veri analizi ve yazının hazırlanması: EYK
Veri toplama ve yazının hazırlanması: SK

\section{Kaynaklar}

1. Leventhal H, Leventhal EA, Cameron L. Representations, procedures, andaffect in illness self-regulation: a perceptualcognitive model. In: Baum A, Revenson TA, Singer JE, editors. Handbook of health psychology. Mahwah: Lawrence Erlbaum; 2001. p.19-48.

2. Armay Z, Özkan M, Kocaman N, Özkan S. Hastalık algısının ölçeğinin kanser hastalarında Türkçe geçerlik ve güvenirlik çalışması. [The Turkish reliability and validity study in cancer patients of illness perception questionnaire] Klinik Psikiyatri [Clinical Psychiatry] 2007;10:192-200.

3. Petrie JK, Weinman J. Why illness perceptions matter.Clin Med 2006; 6(6):536-539.

4. Petrie JK, Jago AL, Devhich DA. The role of illness perceptions in patients with medical conditions. Current Opinion in Psychiatry 2007;20(2):163-167.

5. Hagger MS, Orbell S. A meta-analytic review of the common-sense model of illness representations. PsycholHealth 2003;18(2):141-84.

6. Weinman J, Petrie KJ, Moss-Morris R, Horne R. The Illness Perception Questionnaire: A new method for assessing the cognitive representation of illness. Psychol Health 1996;11(3):431-445.

7. Yeon Kye S, Young Park E, Oh K, Park K.Perceptions of cancer risk and cause of cancer risk in korean adults. Cancer Res Treat. 2014 Sep 1547(2): 158-165. Available from:

http://www.ncbi.nlm.nih.gov/pubmed/2548 3748/DOI:10.4143/crt.2014.024.

8. Tan M, Karabulutlu E. Social Support and hopelessness in Turkish patients with cancer. Cancer Nursing 2005;28(3):236240.

9. Tuncay T. Genç Kanser Hastalarının Hastalık Anlatılarının Güçlendirme Yaklaşımı Temelinde Analizi [Analysis of the Illness Narratives of the Young Cancer Patients on the Basis of Empowerment Approach] Toplum ve Sosyal Hizmet 
[Community and Social Services] 2009;20(2):69-87.

10. Traeger L, Penedo FJ, Gonzalez JS, Dahn JR, Lechner SC, Schneiderman N et al. Illness perceptions and emotional wellbeing in men treated for localized prostate cancer. Journal of Psychosomatic Research 2009;67(5):389-397.

11. Dempster M, McCorry KN, Brennan E, Donnelly M, Murray LJ, Jonston TB. Do changes in illness perceptions predict changes in psychological distress among oesophageal cancer survivors?Journal of Health Psychology 2010;16(3):500-509.

12. Zivkovic MV, Dediol I, Ljubicic I, Situm M. Sun behaviour patterns and perception of illness among melanoma patients. JEADV 2011 Jun 21;26(6):724729.Availablefrom:http://www.ncbi.nlm.ni h.gov/pubmed/21689168/ DOI: 10.1111/j.1468-3083.2011.04154.x.

13. McCorry KN, Dempster M,Quinn J,Hogg A, Newell J, Moore M et al. İlness perception clusters at diagnosis predict psychological distress among women with breast cancer at 6 months post diagnosis. Psycho-Oncology 2013;22(3):692-698.

14. Scharloo M, Baatenburg de Jong RJ, Langeveld TPM, Velzen-Verkaik E, Akker MD, Kaptein AA. Illness cognitions in head and neck squamous cell carcinoma: predicting quality of life outcome. Support Care Cancer 2010;18(9):1137-1145.

15. Fischer MJ, Wiesenhaan ME, Heijer AD, Kleijn WC, Nortier JWR, Kaptein AA. From despair to hope: A longitudinal study of illness perceptions and coping in a psycho-educational group intervention for women with breast cancer. British Journal of Health Psychology 2013;18(3):526-545. 16. Wu LM, Mohammed NE, Winkel G, Diefenbach MA. Patient and spouse illness beliefs and quality of life in prostate cancer patients. Psychol Health. 2013;28(4):355368.

17. Iskandarsyah A, Klerk C, Suardi DR, Sadarjoen SS, Passchier J. Consulting a traditional healer and negative illness perceptions are associated with nonadherence to treatment in Indonesian women with breast cancer. PsychoOncology 2014;23(10):1118-1124.

18. Castillo DA, Godoy-Izquierdo D, Vazquez ML, Godoy JF. İllness beliefs about cancer among healthy adults who have and have not lived with can cerpatients. International Society of Behavioral Medicine 2011 Dec;18(4):342351. Available from: http://www.ncbi.nlm.nih.gov/pubmed/2130 8426/DOI 10.1007/s12529-010-9141-6.

19. Hopman P, Rijken M. İllness perceptions of cancer patients: relationships with illness characteristics and coping. Psycho-Oncology 2015; 24(19):11-18.

20. Keeling M, Bambroigh J, Simpson J. Depression, anxiety and positive affect in people diagnosed with low-grade tumours: the role of illness perceptions. PsychoOncology 2013;22(6):1421-1427.

21.Richters A, Derks J, Husson O, Van Onna IE, Fossion LM, Kil PJ, et al. Effect of surgical magrin status after radical prostatectomy on health-related quality of life and illness perception in patients with prostate cancer. Urologic Oncology 2015;33(1):9-15.

22. Kayır G. Onkoloji hastalarının hastalık alg1sı ve Stresle başa çıkma biçimleri [Disease perception of oncology patients and their ways to deal with stress] [Yüksek Lisans]. İstanbul Üniversitesi Sağl1k Bilimleri Enstitüsü [Istanbul University Institute of Health Sciences] İstanbul, Türkiye, 2014.

23. Kayış A. Kanser hastalarının hastalık algısı ve umutsuzluk düzeyleri [İllness perception and hopelessness levels in cancer patients] [Yüksek Lisans]. Haliç Üniversitesi Sağlık Bilimleri Enstitüsü [İnstitude of Medical Sciences, Haliç Üniversity], İstanbul, Türkiye, 2009.

24. Kocaman N, Özkan M, Armay Z, Özkan S. Hastalık Algısı Ölçeğinin Türkçe uyarlamasının geçerlilik ve güvenilirlik çalışması. [The reliability and the validity study of Turkish adaptation of the revised Illness Perception Questionnaire] Anadolu Psikiyatri Dergisi [Anatolian Journal of Psychiatry] 2007;8(4):271-280. 
25. Minton $\mathrm{O}$, Berger $\mathrm{A}$, Barsevick $\mathrm{A}$, Cramp F, Goedendorp M, Mitchell SA, et al. Cancer-related fatigue and its impact on functioning. Cancer 2013;119(11):21242130.

26.Zordan R, Manitta V, Nandurkar H, Cole-Sinclair M, Philip J. Prevalence and predictors of fatigue in haemooncological patients. Internal Medicine Journal 2014;44(10):1013-1017.

27.Rüffer JU, Flechtner H, Tralls P, Josting A, Sieber M, Lathan B et al. Fatigue in longterm survivors of Hodgkin'slymphoma; a report from the German Hodgkin Lymphoma Study Group (GHSG). Eur J Cancer 2003;39(15):2179-2186.

28. Bağ B. Kanser hastalarında uzun dönemde görülen sorunlar. [Long term psychosocial problems in cancer patients] Psikiyatride Güncel Yaklaşımlar [Current Approaches in Psychiatry] 2013;5(1):109126.

29. Turan Kavradım S, Canlı Özer Z. Kanser tanisı alana hastalarda umut [Hope in patients with cancer]. Psikiyatride Güncel Yaklaşımlar [Current Approaches in Psychiatry] 2014;6(2):154-164.

30. Gültekin M, Özgül N, Olcayto E, Tuncer M. Kanser ve kanser risk faktörleri hakkında Türk Halkı'nın bilgi düzeyinin ölçülmesi ve araştırılması. [Level of knowledge among Turkish people for cancer and cancer risk factors] Journal of Turkish Society of Obstetrics and Gynecology[J Turk Soc Obstet Gynecol] 2011;8(1):57-61.

31.Mallinger JB, Griggs JJ, Shields CG.

Patient centered care and breast cancersurvivors' satisfaction within formation. Patient Educ Couns 2005;57(3):342-349.

32. Husson O, Thong MSY, Mols F, Oerlemans S, Kaptein AA, Poll-Franse LV. Illness perceptions in cancer survivors: what is the role of information provision? Psycho-Oncology 2013;22(3):490-498.

33. Lam WWT, Au AHY, Wong JHF, Lehmann C, Koch U, Fielding $\mathrm{R}$ et al. Unmet supportive care needs: a crosscultural comparison between Hong Kong
Chinese and German Caucasi an women with breast cancer. Breast Cancer Res Treat 2011;130(2):531-541.

34. Açıkgöz A, Çehreli R, Ellidokuz H. Kadınların kanser konusunda bilgi ve tutumları ile erken tanı yöntemlerine yönelik davranışları. [Women's knowledge and attitude about cancer and the behaviour for early diagnosis procedures]DEÜ Tip Fakültesi Dergisi [DEU Journal of Faculty of Medicine] 2011;25(3):145-154.

35. Ülger E, Alacacıoğlu A, Gülseren AŞ, Zencir G, Demir L, Tarhan MO. Kanserde psikososyal sorunlar ve psikososyal onkolojinin önemi [Psychosocial problems in cancer and the importance of psychosocial oncology] DEÜ Tıp Fakültesi Dergisi [DEU Journal of Faculty of Medicine] 2014;28(2):85-92.

36. Ateşçi FÇ, Oğuzhanoğlu NK, Baltalarlı B, Karadăg F, Özdel O, Karagöz N. Kanser Hastalarında Psikiyatrik Bozukluklar ve İlişkili Etmenler [Psychiatric Disorders in Cancer Patients and Associated Factors]. Türk Psikiyatri Dergisi [Turkish Journal of Psychiatry] 2003;14(2):145-152.

37. Aksu T, Okçay H. Yaşam Dönemlerine Göre Ölüm Algısı ve Hemşirelik Yaklaşımı[Death Perception to Life Periods and Nursing Approach] Firat Sağlik Hizmetleri Dergisi 2010;14(5):113-126.

38. Özkan S. Kanser hastas1- aile- tedavi ekibi.[Cancer patients-family-treatment team] Psiko-onkoloji. 1. bask1. İstanbul: Form Reklam Hiz; 2007. p.169-185.

39. Işık I. Meme kanseri hastalarında tedavi sonrası dönemde gelişen psikososyal sorunlar ve destekleyici hemşirelik girişimleri.[Psychosocial problems of breast cancer patients in the post-treatment period and supportive nursing interventions] Hemşirelikte eğitim ve araştırma dergisi [Journal of educationandresearch in nursing] 2014;11(3):58-64.

40.Jorgensen LI, Frederiksen K, Boesen E, Elsaa P, Johansen C. An exploratory study of associations between illness perceptions and adjustment and changes after psychosocial rehabilitation in survivors of 
breast cancer. Acta Oncologica prognostik faktörlerle birlikte 2009;48(8):1119-1127.

komorbiditelerin sağkalım üzerine olan 41. Rozema H, Völlink T, Lechner. The role etkisinin değerlendirilmesi [Uzmanlık of illness representations in coping and health of patients treated for breas tcancer. Psycho-Oncology 2009;18(8):849-857.

42. Kaya M. İleri yaştaki küçük hücreli dışı akciğer kanserli hastalarda klasik Tezi]. Başkent ÜniversitesiTıp Fakültesi İç Hastalıkları Anabilim Dalı [Başkent University Faculty of Medicine, Department of Internal Medicine], Ankara, Türkiye, 2013. 